\title{
A ADESÃO À OCDE: "MUITO BARULHO POR NADA?" 1
}

\author{
Carlos A. Primo Braga²
}

A candidatura brasileira com o intuito de se tornar membro da Organização para a Cooperação e Desenvolvimento Econômico (OCDE) gera uma série de perguntas sobre as implicações desse processo para a economia brasileira e a estratégia do país para a integração econômica. Aqueles que apoiam a adesão argumentam que isso ajudará na adoção das melhores práticas em termos de governança e políticas regulatórias. A expectativa é que ela promova a liberalização do comércio, atraia investimentos estrangeiros diretos e tenha um impacto positivo sobre a produtividade. Este artigo alega que, embora a adesão possa ter impactos líquidos positivos para o Brasil, não se deve subestimar as dificuldades inerentes a esse processo, nem superestimar o potencial de transformação estrutural associado à adesão à OCDE.

Palavras-chave: OCDE; processo de adesão; liberalização do comércio; política comercial brasileira.

\section{THE ACCESSION TO THE OECD: "MUCH ADO ABOUT NOTHING?"}

The Brazilian candidacy to become a member of OECD generates a series of questions about the implications of this process for the Brazilian economy and the country's strategy for economic integration. Those who support the accession to OECD argue that this will help with the adoption of best practices in terms of governance and regulatory policies. The expectation is that the accession will promote trade liberalization, attract foreign direct investment and have a positive impact on productivity. This paper argues that even though the accession may have net positive impacts for Brazil, one should not underestimate the difficulties of the process, nor overestimate the potential for structural transformation associated with OECD accession.

Keywords: OECD; accession process; trade liberalization; Brazilian trade policy.

\section{LA ADHESIÓN A LA OCDE: "MUCHO RUÍDO Y POCAS NUECES?"}

La candidatura de Brasil a miembro de la OCDE genera una serie de preguntas sobre las implicaciones de este proceso para la economía brasileña y la estrategia de integración económica del país. Los que apoyan la adhesión a la OCDE argumentan que esto ayudará a la adopción de las mejores prácticas en términos de gobernanza y políticas regulatorias. Se espera que la adhesión promueva la liberalización del comercio, atraiga la inversión extranjera directa y tenga un impacto positivo en la productividad. Este documento sostiene que, aunque la adhesión puede tener impactos positivos netos para Brasil, no hay que subestimar las dificultades del proceso, ni sobreestimar el potencial de transformación estructural asociado a la adhesión a la OCDE.

\footnotetext{
1. Cooperei com a Organização para a Cooperação e Desenvolvimento Econômico (OCDE) em diferentes modalidades, seja como Conselheiro Sênior, Comércio Internacional do Banco Mundial (2003-2006), quando estava baseado em Genebra e participava dos encontros do Comitê de Comércio da OCDE. No período 2008-2010, como diretor do Departamento de Política Econômica e Dívida do Banco Mundial, coeditei um livro (Innovation and Growth: chasing a moving frontier) e, posteriormente como diretor de relações externas (2011-2012), fui responsável por coordenar as relações entre o Banco Mundial e a OCDE. Admiro o trabalho da organização e os comentários neste artigo refletem a minha visão das implicações do eventual acesso do Brasil à OCDE de uma perspectiva acadêmica. Evidentemente, esses comentários têm um caráter pessoal e não devem ser associados com as organizações aqui referidas.

2. Professor associado da Fundação Dom Cabral. E-mail: <cbraga.associado@fdc.org.br>. Orcid: <https://orcid. org/0000-0001-8434-6217>.
} 
Palabras clave: OCDE; proceso de adhesión; liberalización comercial; política comercial brasileña. JEL: F02; F10; F13.

DOI: http://dx.doi.org/10.38116/rtm25art4

Data de envio do artigo: 23/11/2020. Data de aceite: 23/12/2020.

\section{INTRODUÇÃO}

O Brasil tem um histórico de interaçôes crescentes com a Organização para a Cooperação e Desenvolvimento Econômico (OCDE) desde os anos 1990. Inicialmente, atuou no contexto da política de engajamento da organizaçâo com a América Latina; em 1996, passou a participar no Comitê do Aço (Steel Committee); e tornou-se membro do Centro de Desenvolvimento da OCDE em 1997, ano em que aderiu às Diretrizes para Empresas Multinacionais (Guidelines for Multinationals Enterprises). Em 2000, tornou-se signatário da Convenção Anti-Suborno (Anti-Bribery Convention and Recommendation of the Council Against Hard Core Cartels) e, em 2007, foi convidado a participar como um dos países identificados para engajamento ampliado (enhanced engagement, posteriormente caracterizados como parceiros-chave, ou key partners). ${ }^{3}$ Finalmente, o Brasil apresentou formalmente a sua aplicação para se tornar membro da OCDE em 2017, durante o governo Temer.

De uma forma genérica, as reaçôes da comunidade acadêmica e de diplomatas (ativos e aposentados) à decisão brasileira de solicitar acesso à OCDE podem ser classificadas em duas posiçôes antagônicas. De um lado, há aqueles que acreditam que o processo de adesão trará oportunidades para aprimorar o ambiente de negócios no Brasil, favorecendo a adoção de boas práticas com relação a governança corporativa, políticas do setor público e tratamento do investimento estrangeiro, que favoreceriam o aumento de produtividade na economia brasileira e o crescimento econômico. Outros, porém, adotam uma visão mais crítica, argumentando que a entrada do Brasil no "Clube dos Ricos" viria a comprometer a liderança diplomática histórica do Brasil em áreas de interesse de países em desenvolvimento, como as articuladas pelo G77 e em negociações multilaterais de comércio. Não apenas isso, mas também argumentam que a afinidade do Brasil com a maioria dos países-membros da OCDE é limitada de um ponto de vista econômico, social e em termos de interesses estratégicos. Nesse contexto, observam que o Brasil deveria explorar uma articulação com os demais BRICS 4 com o intuito de alavancar uma agenda de reformas na OCDE em maior consonância com os objetivos de uma nação em desenvolvimento e que

3. Outros países convidados nesse contexto foram a China, Índia, Indonésia, e África do Sul.

4. Brasil, Rússia, Índia, China e África do Sul. 
precisa manter flexibilidade na determinação do seu espaço de implementação de políticas públicas (policy space). ${ }^{5}$

Tais caracterizações são, de certa forma, caricaturas das posiçôes sendo proferidas por diferentes analistas. Cabe observar, por exemplo, que a OCDE há muito não é mais um clube exclusivo de países ricos. A Turquia, em 1961, o México, em 1994 e a Colômbia, em 2020, se tornaram membros da organização, e, como o Brasil, são países de renda média elevada - classificação feita pelo Banco Mundial -, já que tinham uma renda nacional bruta (gross national income GNI) per capita em 2019 entre US\$ 4.406 e US\$ 12.535. Mesmo o Chile, que ingressou na organizaçáo em 2010, e na atualidade tem status de economia de alta renda (com uma GNI per capita de US\$15.010 em 2019), era uma economia de renda média elevada no momento da sua adesão ao "clube". Entretanto, o impacto econômico da adesão à OCDE não é necessariamente transformador, como ilustrado pelo caso do México, discutido ao longo do texto.

As seções que seguem discutem o significado da acquis da OCDE e até que ponto os acordos da organização exigirão uma mudança significativa nas políticas do país. $\mathrm{O}$ artigo também discute como essas mudanças poderão impactar questôes como produtividade e a política comercial brasileira. A posição adotada neste artigo é de que muitas das recomendaçóes implícitas nos acordos da OCDE são úteis como referência de boas práticas internacionais - ao mesmo tempo, elas não constituem uma "bala de prata" para resolver os grandes problemas de desenvolvimento enfrentados pelo país. Além disso, o processo de adesão será longo e complexo, de forma que é um equívoco ter ilusôes sobre o seu impacto a curto prazo.

\section{A OCDE E OS SEUS PRINCÍPIOS}

As origens da OCDE remontam ao Plano Marshall e aos esforços de financiar a recuperação das economias europeias após a Segunda Guerra Mundial. Em 1948, a Organização Europeia de Cooperação Econômica (Organisation for European Economic Co-Operation - OEEC) foi criada, incluindo, originalmente, dezoito participantes representando países europeus, a Turquia, e, inicialmente, zonas de ocupação aliada, como a Alemanha Ocidental e a Zona Anglo-Americana do Território Livre de Trieste. A OEEC teve um papel importante na preparação do Programa de Recuperação Europeia e na alocação dos recursos do Plano Marshall de ajuda norte-americana à reconstrução da Europa.

Em 1961, a OCDE substituiu a OECC. Em seu início, a OCDE incluiu os países fundadores da OECC, os Estados Unidos e o Canadá. Os vinte países

5. Para uma análise desses posicionamentos, ver Santos (2018). 
que originalmente assinaram a Convenção da OCDE, em 14 de dezembro de 1960, eram, em tese, democracias compromissadas com a adoção de políticas que promovem crescimento econômico, prosperidade e desenvolvimento sustentado. Como observado em Martens e Jacobi (2010), a OCDE nasceu como uma organização intergovernamental que serviria como um contraponto à aliança militar da Organização do Tratado do Atlântico Norte (OTAN). A OCDE herdou a estrutura institucional da OEEC, mas não manteve a capacidade de financiamento e de impor condicionalidades daquela organização.

Nos seus primeiros trinta anos, a OCDE expandiu a sua composição lentamente, com a adesão de Itália, em 1962; Japão, em 1964; Finlândia, em 1969; Austrália, em 1971; e Nova Zelândia, em 1973. Após o colapso da União Soviética, a expectativa era de que uma rápida expansão ocorreria com o acesso de países do Leste Europeu. Tal previsão se concretizou parcialmente com a adesão de República Tcheca em 1995; Hungria, em 1996; Polônia, em 1996; e a República Eslovaca, em 2000. Ao mesmo tempo, havia uma preocupação em distanciar a organização das suas origens "europeias", com o objetivo de posicionar a OCDE como uma organização global. Nesse contexto, o México, em 1994, paralelamente à sua adesão ao Acordo de Livre Comércio da América do Norte (North American Free Trade Agreement - NAFTA), e a Coreia do Sul, em 1996, também se tornaram membros da OCDE.

Em 2010, um novo ciclo de expansão foi iniciado com a adesão de quatro países (Chile, Israel, Eslovênia e Estônia). Nos anos seguintes, Letônia, em 2016; Lituânia, em 2018; e Colômbia, em 2020, se tornaram membros da OCDE. ${ }^{6}$ Com a adesão da Colômbia, a organização passou a contar com 37 membros, que respondem por cerca de $62 \%$ do produto interno bruto (PIB) global, sendo $68 \%$ países-membros europeus.

$\mathrm{O}$ processo de acesso à $\mathrm{OCDE}$ é rigoroso e, em princípio, tem como objetivo garantir um grau de homogeneidade entre os países-membros. Embora, como já mencionado, a caracterização da OCDE como o "clube dos países ricos" seja uma descrição ultrapassada, a participação no "clube" requer um compromisso com princípios econômicos liberais, um sistema democrático pluralista e respeito a direitos humanos. ${ }^{7} \mathrm{O}$ acesso requer que o país satisfaça, em sua legislação doméstica, a conformidade com a acquis da OCDE, que reflete

6. Após ter iniciado seu processo de adesão em 2015, Costa Rica foi formalmente convidada a se tornar o 38 membro da OCDE em maio de 2020. 0 acesso será finalizado uma vez que o governo complete as medidas domésticas para a sua aprovação e o instrumento de adesão à Convenção da OCDE seja depositado.

7. De acordo com o 50th Anniversary Vision Statement: "OECD Members continue to form a community of nations committed to the values of democracy based on the rule of law and human rights, and adherence to open and transparent market-economy principles" (OECD, 2011, p. 2). 
cerca de 248 instrumentos legais, entre decisōes, recomendaçóes, declarações, acordos internacionais e outros instrumentos. ${ }^{8}$

A atuação da OCDE evoluiu com o tempo, e a organização, que nas suas origens atuava como uma think tank de países desenvolvidos, passou a ter um papel crescente no estabelecimento de padrôes internacionais para esforços de coordenação na área tributária, com respeito ao combate à corrupçáo, vis-à-vis investimentos estrangeiros, e à ajuda externa. Algumas dessas iniciativas, como o Acordo Multilateral de Investimentos, enfrentaram oposição de países em desenvolvimento e de organizaçóes não governamentais e não chegaram a ser implementadas. Entretanto, a OCDE - no contexto das gestôes do secretário geral Angel Gurria (2006-2021) - se posicionou como uma espécie de secretariado informal do G20 no período pós-crise financeira global.

Atuando em colaboração com o Fundo Monetário Internacional (FMI) e o Banco Mundial, a OCDE tem sido uma das organizaçóes internacionais mais ativas no preparo de trabalhos de apoio às deliberaçôes do G20. ${ }^{9}$ Não apenas isso, mas a organização vem também desenvolvendo trabalhos pioneiros com respeito à economia digital - e, em particular, tributação no ambiente digital e ampliando os esforços para a implementação do Combate à Erosão da Base Tributária e à Transferência de Lucros (Inclusive Framework on Base Erosion and Profit Shifting - BEPS), regras plurilaterais envolvendo cerca de 135 países que têm como objetivo coibir práticas tributárias estratégicas adotadas por empresas multinacionais para evitar o pagamento de impostos.

Essas consideraçóes podem ser utilizadas como argumentos favoráveis à proposição de que faz sentido para o Brasil, como membro do G20 e uma das dez maiores economias do mundo, investir no processo de adesão à OCDE. Dessa forma, o Brasil poderá não apenas se beneficiar do acesso a dados comparativos internacionais, mas também se envolver mais diretamente na produção desses. Além disso, na medida em que há uma expectativa de que a OCDE continuará a ter um papel relevante na elaboração de padrôes internacionais - particularmente no que tange ao futuro da economia digital -, a adesão permitiria que o Brasil participasse na construção desses padrōes. Evidentemente, tais benefícios são acompanhados de custos, como discutido na próxima seção.

8. Mais informações em Thorstensen et al. (2020) e Cozendey (2020).

9. Os encontros ministeriais do G20 começaram a ocorrer em 1999. A partir de 2008, ele passou a ter também encontros de chefes de Estado, tornando-se a mais influente plataforma de coordenação para a elaboração de respostas a crises econômicas internacionais. Alguns analistas têm explicitamente sugerido que a OCDE poderia se tornar o secretariado formal de um G20 adaptado às atuais realidades da economia mundial (Solana, 2020). 


\section{PROCESSO DE ADESÃO}

A avaliação da candidatura de um país à OCDE é desenvolvida com base em um quadro de referência (framework) padrão que analisa os seguintes aspectos: i) grau de adequação do país com respeito a indicadores econômicos, de funcionamento do mercado, do sistema tributário e do sistema financeiro; ii) grau de compromisso do país com relação aos valores da OCDE e às obrigaçóes inerentes ao acquis da organização; iii) qualidade das instituiçóes, incluindo o tipo de governo e as características do sistema legal do país; iv) histórico de relaçóes com a OCDE; e v) nível de comprometimento do governo com relação ao uso do processo de adesão para alavancar a agenda de reformas domésticas (OECD, 2017).

O Brasil e outros cinco países (Argentina, Peru, Romênia, Croácia e Bulgária) são, no momento, candidatos para adesão à $\mathrm{OCDE} .{ }^{10}$ Análises baseadas no grau de engajamento desses candidatos, bem como de outros parceiros-chave, sugerem que o Brasil se posiciona relativamente bem em termos do número de instrumentos consistentes com a legislação e práticas nacionais. De acordo com Cozendey (2020), o Brasil já atende aos requisitos de conformidade em cerca de 96 instrumentos da OCDE e encontra-se em processo de adesão aos outros 46. Cabe também assinalar que o Brasil vem aumentando a sua participação em comitês e órgãos da OCDE e esse tipo de engajamento, que se acelerou a partir de 2017 , posiciona bem o país vis-à-vis outros candidatos. ${ }^{11}$

Permanece, porém, a questão de quais são os instrumentos que irão exigir ajustes legais e negociação política para adequação das práticas brasileiras ao acquis da OCDE. Estimativas variam, mas como observado em Cozendey (2020), cerca de trinta instrumentos, ou seja, 12\%, estariam nessa categoria. Alguns exemplos nesse contexto incluem a abordagem brasileira com relação a preços de transferência, à política tributária, e ao tratamento de fluxos de capitais. A política de meio ambiente e de comércio exterior também serão alvos de críticas em virtude de percepçóes internacionais, desencontros da política nacional e o histórico protecionista do Brasil.

O tratamento de transaçóes internacionais entre empresas do mesmo grupo corporativo (subsidiárias, coligadas etc.) com relação às regras de determinação de preços de transferência é um dos temas mais controversos no que tange a discrepâncias entre as práticas brasileiras e as regras da OCDE. As normas legais visam proteger a base tributária do país e evitar distorçôes na determinação dos

10. Cabe assinalar que a Rússia teve o seu processo de adesão à OCDE interrompido em março de 2014 em virtude de uma decisão do Conselho da OCDE no contexto da crise da Crimeia.

11. No caso de participação em órgãos, esse número cresceu de 22 em 2017 para 32 em 2020 (Cozendey, 2020; Mello, 2020). 
preços praticados por multinacionais, de forma a manter um tratamento similar aos preços praticados entre partes não relacionadas, ou seja, transaçóes de acordo com o princípio de relaçôes arm's length (ALP) em transaçôes internacionais.

As discrepâncias entre a abordagem brasileira e as regras da OCDE são substantivas. ${ }^{12}$ Elas incluem o uso limitado da abordagem ALP nas relaçóes entre empresas e a ênfase em margens predeterminadas; a falta de regras específicas para serviços intragrupos, para a transferência de intangíveis e para o tratamento de royalties; bem como a flexibilidade conferida ao contribuinte na escolha do método de cálculo do preço de transferência. Em muitos casos, essas discrepâncias aumentam o risco de dupla tributação e geram desincentivos ao comércio internacional e aos investimentos. Alguns analistas argumentam que a legislação brasileira é compatível com as diretrizes da OCDE, muito embora reconheçam que ela possa ser aprimorada. ${ }^{13}$ De qualquer forma, é evidente que esse tema será um dos aspectos mais controversos nas negociaçóes para a adesão do país à OCDE.

Outro tema que exigirá adaptaçóes no caso brasileiro diz respeito ao nosso sistema tributário. A simplificação dos tributos sobre consumo, como o Imposto sobre Serviços (ISS) e o Imposto sobre Circulação de Mercadorias, Bens e Serviços (ICMS), é uma prioridade nacional. Entretanto, as diferenças em alíquotas entre entidades federativas e a complexidade do sistema vêm sendo debatidas no Congresso e são também objeto de iniciativas do poder Executivo. ${ }^{14} \mathrm{~A}$ falta de consenso nesse tema ilustra a dificuldade que o país enfrentará na medida em que o sistema vigente favorece uma tributação descoordenada de impostos no comércio transfronteiriço.

Evidentemente é possível encontrar várias outras áreas onde existem discrepâncias entre as práticas brasileiras e as diretrizes da OCDE, como o tratamento de pagamentos por transferência de tecnologia, mas é no campo político que percepçóes, diferenças de política comercial e alianças estratégicas irão influenciar o processo de adesão. No que tange a percepçôes, é ilustrativo observar o debate atual sobre o Acordo de Associação Mercosul-União Europeia (28 de junho de 2019). O Brasil vem sendo caracterizado como um "vilão" no contexto de suas políticas ambientais e as implicações do desmatamento ilegal na Amazônia. Como consequência, a oposição ao Acordo, mais especificamente ao acordo de comércio, vem aumentando não apenas em vários parlamentos

12. Disponivel em: <http://www.oecd.org/tax/transfer-pricing/declaracao-conjunta-projeto-precos-de-transferenciaocde-brasil-julho-2019.pdf>.

13. Disponível em: <https://www.ibet.com.br/manifesto-a-declaracao-conjunta-sobre-projeto-de-precos-de-transferenciaocde-brasil/>.

14. Essa questão está sendo discutida no contexto da Proposta de Emenda Constitucional (PEC) № 45/2019, PEC no 110/2019 e no Projeto de Lei oㅜ 3.887/2020. 
nacionais, como a Áustria, mas também em Bruxelas. Em outubro de 2020, o Parlamento Europeu aprovou uma emenda que argumenta que o Acordo não poderá ser ratificado em seu formato original em virtude de inquietudes com relação à política ambiental da administração Bolsonaro. É bem verdade que essa emenda não tem um caráter compulsório, mas ela simboliza as percepçóes negativas que certamente influenciarão o apoio europeu ao processo de adesão do Brasil à OCDE.

Um outro exemplo de como mudanças políticas domésticas podem afetar as percepções sobre a qualidade das instituiçôes brasileiras e a consistência das políticas nacionais com as diretrizes da OCDE diz respeito aos mecanismos de combate à corrupção. O Brasil é membro do Grupo de Ação Financeira contra a Lavagem de Dinheiro (GAFI) desde 2000, estabelecido em 1989 pelos países do G7 com o objetivo de analisar técnicas de lavagem de dinheiro e como coibir as mesmas a nível internacional. Em 2001, a questão do combate ao financiamento do terrorismo foi acrescentada à agenda. As práticas brasileiras no combate à lavagem de dinheiro, em particular com relação ao financiamento de terrorismo, têm sido criticadas com frequência no âmbito das avaliaçóes do GAFI. Em 2019, porém, as críticas foram ampliadas quando da decisão do entẫo presidente do Supremo Tribunal Federal, José Antonio Dias Toffoli, de impor limitaçóes ao compartilhamento de dados de inteligência financeira obtidos pelo Conselho de Controle de Atividade Financeira (COAF) no caso de investigaçóes judiciais. Embora tal decisão tenha sido alterada posteriormente, a percepção de insegurança jurídica e o fato de o GAFI trabalhar em sintonia com a OCDE - como o Comitê de Assuntos Fiscais e a convençáo da OCDE contra o suborno de funcionários públicos estrangeiros em transaçóes comerciais internacionais - pode contribuir para prejudicar a avaliação de como o Brasil se adequa às diretrizes da OCDE com relação ao combate à corrupção e a lavagem de dinheiro.

Alianças e preferências regionais também influenciarão o processo. Existem no momento três países europeus (Romênia, Croácia e Bulgária) na fila para a adesão à OCDE. No caso da Bulgária, a Uniâo Europeia tem indicado que o processo de adesão deve ser iniciado formalmente antes do Brasil. ${ }^{15}$ Cabe assinalar que o Brasil obteve o apoio explícito da administração Trump em março de 2019 para o início do seu processo de adesão à OCDE. ${ }^{16}$ Evidentemente, a continuidade do apoio norte-americano ao Brasil é uma questáo em aberto, dada a troca de guarda na Casa Branca em 2021.

15. No caso da Croácia, disputas com a Eslovênia sobre fronteiras têm impedido progresso, e no caso da Romênia, tensões com a Hungria com respeito aos direitos de minorias também vêm afetando as discussões.

16. Para obter esse apoio, a administração Bolsonaro se comprometeu a abandonar o uso de tratamento especial e diferenciado disponível para países em desenvolvimento no contexto de negociações futuras na Organização Mundial de Comércio $(\mathrm{OMC})$. 
As discrepâncias entre o regime de política comercial brasileira e as práticas típicas de países da OCDE constituem uma outra área de tensôes potenciais. Muito embora o processo de adesão à $\mathrm{OCDE}$ não envolva concessões em termos de acesso à mercado, é evidente que essas discrepâncias serão foco de debate no contexto das negociaçôes. Esse ponto será mais discutido na seção 5 .

\section{QUE MOTIVA UM PAÍS A EXPLORAR ADESÃO À OCDE? ${ }^{17}$}

A participação em "clubes" gera custos e benefícios. No caso da OCDE, os custos estâo associados com a necessidade de se adequar ao seu acquis, como discutido na seção anterior, bem como o custo da contribuição para o seu orçamento. Estimativas de quanto seria a contribuição anual do Brasil, baseadas nos critérios utilizados para definir a contribuição dos seus membros, sugerem que o custo - no contexto da Parte I do Orçamento, que diz respeito a contribuiçóes obrigatórias - seria da ordem de 15 milhôes de euros/ano (Thorstensen et al., 2020, p. 20). Esse preço não é, em princípio, um óbice à participação brasileira, muito embora o país esteja em atraso no que tange às suas contribuiçôes para várias organizaçōes internacionais na atualidade.

Os custos de ajuste da legislaçấo brasileira e do comportamento de agentes econômicos às novas regras, por sua vez, podem ser significativos, quer em termos do capital político que o governo terá de investir para assegurar mudanças legislativas, quer com respeito a mudanças de práticas de negócios, quer em virtude da incerteza jurídica durante o período de transição.

Entre os benefícios que a entrada do Brasil na OCDE pode gerar, merecem uma atenção especial: i) a participação na elaboração de regras e padróes internacionais para diferentes áreas de atividade econômica; ii) a utilização das diretrizes da OCDE como referência e "âncora” para a implementação de reformas administrativas e regulatórias; iii) a promoção de um ambiente para a realização de negócios mais transparente e consistente com padróes internacionais, inclusive com respeito à governança de empresas estatais; e iv) a sinalização da capacidade do país em exercer influência diplomática (soft power) de forma coordenada a nível internacional, por exemplo, no contexto das discussões sobre ajuda externa conduzidas pelo Comitê de Ajuda ao Desenvolvimento (Development Assistance Committee - DAC) da OCDE.

Com relação ao papel da OCDE como organização-chave para o estabelecimento de padróes internacionais, uma área relevante diz respeito à economia digital e, em particular, a questão da tributação do comércio eletrônico. Esse tema é de importância crescente, e dada a crise atual da OMC, a OCDE vem se posicionando como o fórum mais ativo para discussóes relacionadas com o futuro da economia digital. Regras sobre o tratamento do capital estrangeiro, bem como sobre

17. Essa seção se beneficia das análises em Primo Braga e Cattaneo (2009; 2011) com respeito à lógica por trás da decisão de um país em explorar a adesão à OMC. 
o combate à corrupção, e a implementação do projeto que foca na Erosão da Base Tributária e Transferência de Lucros (Base Erosion and Profit Shifting-BEPS) como ferramenta para coibir práticas de evasão tributária por companhias multinacionais são outras áreas relevantes em que a $\mathrm{OCDE}$ tem um papel de protagonismo em termos de formulação e implementação de regras internacionais.

No entanto, é no âmbito da aprimoração do ambiente de negócios e do seu potencial impacto sobre políticas de comércio internacional que a adesão à OCDE gera expectativas mais significativas. A narrativa tradicional é de que o processo de adesão irá favorecer o viés liberal da administração Bolsonaro no que tange a políticas comerciais, levando à redução dos altos níveis de protecionismo, que historicamente têm caracterizado a economia brasileira. ${ }^{18}$

\section{IMPACTO POTENCIAL DA ADESÃO À OCDE SOBRE A POLÍTICA COMERCIAL BRASILEIRA ${ }^{19}$}

A estratégia de industrialização por substituição de importaçóes no período pós-Segunda Guerra Mundial gerou incentivos para o investimento estrangeiro direto (IED) - já que era difícil contestar o mercado brasileiro através do comércio - e contribuiu para uma estrutura industrial integrada, mas também caracterizada por baixos níveis de produtividade.

Os limites do modelo em questão ficaram evidentes nos anos $1980 \mathrm{em}$ meio a desequilíbrios macroeconômicos e à crise da dívida externa. Um esforço inicial de liberalização comercial foi implementado nos anos 1990 - no novo milênio, no entanto, essa trajetória foi interrompida. $\mathrm{O}$ superciclo de commodities, alimentado pela expansão acelerada da economia chinesa, facilitou o retorno de uma estratégia intervencionista na medida em que o viés antiexportador, gerado pelas políticas protecionistas, era atenuado pelo impacto positivo da elevação dos termos de troca das exportaçóes brasileiras.

O grau de fechamento da economia brasileira costuma surpreender a maioria dos analistas. Canuto, Fleischhaker e Schellekens (2015) notam que a economia brasileira é a mais fechada entre as economias do G20, como ilustrado pela relação entre comércio internacional de mercadorias (exportaçóes mais importaçôes) e PIB. $\mathrm{Na}$ realidade, no período 2010-2017, esse coeficiente (que em média foi de 25\%) posicionava o Brasil entre as economias mais "fechadas" do mundo, entre os países incluídos no banco de dados do Banco Mundial (Banco Mundial, 2018).

18. É interessante observar que, em 2020, o Brasil, a despeito da pandemia e da crise econômica, continuou a implementar medidas de liberalização econômica. De acordo com o Global Trade Alert (2020), as intervenções de caráter liberalizante foram as mais significativas (em termos de números) entre as economias do G20.

19. Essa seção reflete argumentos desenvolvidos em Primo Braga (2018). 
Uma explicação usual para o baixo envolvimento do Brasil no comércio internacional é articulada com base no tamanho da sua economia. Tipicamente, as grandes economias (em termos de PIB) apresentam uma exposição relativamente menor ao comércio. Tal argumento, porém, não se sustenta com relação ao Brasil: a média de exposição ao comércio internacional como proporção do PIB para as seis maiores economias do mundo é de cerca de 55\% (Canuto, Fleischhaker e Schellekens, 2015). Em outras palavras, o Brasil é um "ponto fora da curva" em termos da sua baixa exposição ao comércio internacional. Cabe observar que o país, em 2019, ocupava a 27a posiçáo como exportador e $28^{a}$ posiçấo como importador de mercadorias nos rankings de participação no comércio internacional da OMC, muito embora estivesse entre as dez maiores economias mundiais em termos do seu PIB naquela época (WTO, 2020).

O modelo de desenvolvimento voltado para dentro e a instabilidade macroeconômica que marcaram o país nas últimas décadas contribuíram não apenas para um desestímulo à produtividade, mas também favoreceram atividades não produtivas (inclusive a corrupção), e a proliferação de intervençóes de caráter burocrático. Com isso, o ambiente de negócios no Brasil é um dos mais complexos do mundo.

Não surpreende, portanto, que a evolução da Produtividade Total dos Fatores (PTF), um indicador da eficiência com que uma economia utiliza os seus fatores de produção de uma forma agregada na geração de produtos, tenha sido negativa no período 2010-2014: uma contração de cerca de -0,815 \% ao ano de acordo com Frischtak, Mourão e Noronha (2017). Tal desempenho indica que a economia brasileira vem se afastando da fronteira tecnológica global nos últimos anos e é consistente com avaliaçóes da queda de competividade internacional, em particular do setor manufatureiro.

A queda da PTF nos últimos anos não se restringe ao Brasil: é um fenômeno generalizado, que vem afetando tanto países industrializados, quanto economias emergentes no período pós-2008. A crise financeira afetou investimentos em ativos intangíveis e de uma forma mais geral em pesquisa e desenvolvimento (P\&D). A crescente incerteza econômica e política nos últimos anos também desestimulou investimentos em projetos de maior risco, ao mesmo tempo em que o desemprego gerou perdas de capital humano, afetando o crescimento da produtividade global. No caso brasileiro, porém, esse náo é um fenômeno conjuntural, na medida em que uma trajetória medíocre de evolução da produtividade pode ser identificada desde os anos 1980.

Em síntese, a estratégia de desenvolvimento brasileira no pós-guerra favoreceu o mercado doméstico, impactando a absorção de novas tecnologias e os incentivos aos investimentos em inovação. Uma recuperação dos níveis de 
produtividade da economia requer não apenas uma revisão da política comercial, mas também esforços complementares nos campos de educação, infraestrutura, sistema tributário, e política tecnológica. Como observado por Solow (s. d. apud Commission on Growth and Development, 2018, p. 16), da mesma forma que uma lista de ingredientes não é suficiente para se preparar um bom prato, uma lista de recomendaçôes de política não é suficiente para estabelecer uma estratégia bem-sucedida de desenvolvimento.

Mesmo assim, merece atenção a tese de que a adoção das boas práticas associadas com as diretrizes da OCDE em áreas de política comercial (por exemplo, recomendaçóes para facilitação de comércio), governança corporativa e tratamento de capital estrangeiro podem alavancar o processo de integraçáo internacional da economia brasileira. Sem dúvida, tais políticas podem favorecer um aumento de competição e, eventualmente, de produtividade na economia.

É importante reconhecer, no entanto, que tais políticas teriam efeitos distintos a nível microeconômico, como discutido em Chandra et al. (2009). Segundo os autores, firmas que se encontram próximas da fronteira tecnológica teriam incentivos para investir em inovaçáo e em esforços para aumento de produtividade e, em contrapartida, firmas que estão distantes da fronteira (e que sobrevivem por causa da proteção associada com as políticas comercial e industrial do país) terão dificuldades para sobreviver, dependendo das dimensóes do choque competitivo. Assim, a realocação de recursos em economias marcadas por grande dispersão setorial de níveis de produtividade pode ser perversa numa fase inicial.

Entretanto, não é apenas a questão da economia política do processo de liberalizaçấo e os custos potenciais do ajuste que devem ser analisados nesse contexto. É correto observar que o México, por exemplo, aumentou significativamente a sua integração com a economia mundial nas últimas décadas, e existe uma correlação em termos dessa trajetória e a adesão à OCDE em 1994. Porém, é um equívoco atribuir causalidade nesse caso. Na realidade, o NAFTA, bem como medidas unilaterais e o impacto de medidas associadas com as negociações multilaterais - como a adesão ao Acordo Geral de Tarifas e Comércio (General Agreement on Tariffs and Trade - GATT) em 1986 e os resultados da Rodada Uruguai - foram os principais fatores por trás desse processo.

Como ilustrado pelos dados da tabela 1, o México, que, como o Brasil, havia seguido uma estratégia de industrialização por substituição de importações, iniciou um processo gradual de liberalizaçấo comercial nos anos 1980. Os resultados desse processo em termos de integração com a economia mundial são evidentes e contrastam com a trajetória brasileira. No entanto, como discutido em Levy (2018), muito embora a estabilidade macroeconômica e uma política 
liberal de comércio tenham sido fatores positivos para a economia mexicana, a produtividade da economia (usando o conceito de PTF) permaneceu medíocre. ${ }^{20}$

TABELA 1

Relação comércio/PIB (1960-2019) (Em \%)

\begin{tabular}{|c|c|c|c|c|c|c|c|}
\hline & 1960 & 1970 & 1980 & 1990 & 2000 & 2010 & 2019 \\
\hline \multicolumn{8}{|l|}{ Brasil $^{1}$} \\
\hline MGS/PIB & 7,17 & 7,45 & 11,31 & 6,96 & 12,45 & 11,91 & 14,65 \\
\hline XGS/PIB & 7,06 & 7,03 & 9,05 & 8,20 & 10,19 & 10,87 & 14,32 \\
\hline Comércio/PIB & 14,23 & 14,48 & 20,36 & 15,16 & 22,64 & 22,78 & 28,97 \\
\hline \multicolumn{8}{|l|}{ Argentina' $^{1}$} \\
\hline MGS/PIB & 7,60 & 4,74 & 6,48 & 4,63 & 11,64 & 16,04 & 15,10 \\
\hline XGS/PIB & 7,60 & 5,60 & 5,06 & 10,36 & 10,99 & 18,93 & 17,29 \\
\hline Comércio/PIB & 15,20 & 10,34 & 11,54 & 14,99 & 22,63 & 34,97 & 32,39 \\
\hline \multicolumn{8}{|l|}{ Peru' } \\
\hline MGS/PIB & 20,27 & 15,58 & 22,12 & 13,77 & 18,77 & 23,85 & 22,94 \\
\hline XGS/PIB & 20,21 & 17,42 & 25,52 & 15,70 & 16,77 & 27,83 & 24,19 \\
\hline Comércio/PIB & 40,48 & 33,00 & 47,64 & 29,47 & 35,54 & 51,58 & 47,13 \\
\hline \multicolumn{8}{|l|}{ México } \\
\hline MGS/PIB & 11,66 & 9,66 & 12,29 & 19,82 & 27,03 & 31,06 & 39,12 \\
\hline$X G S / P I B$ & 8,51 & 7,76 & 11,19 & 20,10 & 25,41 & 29,70 & 39,06 \\
\hline Comércio/PIB & 20,17 & 17,42 & 23,48 & 39,92 & 52,44 & 60,76 & 78,18 \\
\hline \multicolumn{8}{|l|}{ Chile } \\
\hline MGS/PIB & 15,83 & 13,97 & 26,45 & 29,25 & 28,78 & 31,32 & 28,56 \\
\hline$X G S / P I B$ & 13,06 & 14,36 & 21,67 & 32,50 & 30,53 & 37,75 & 28,20 \\
\hline Comércio/PIB & 28,89 & 28,33 & 48,12 & 61,75 & 59,31 & 69,07 & 56,76 \\
\hline \multicolumn{8}{|l|}{ Colômbia } \\
\hline MGS/PIB & 14,76 & 14,56 & 15,60 & 15,92 & 16,75 & 17,92 & 22,20 \\
\hline XGS/PIB & 15,70 & 13,27 & 16,22 & 18,86 & 15,92 & 16,34 & 15,89 \\
\hline Comércio/PIB & 30,46 & 27,83 & 31,82 & 34,78 & 32,67 & 34,26 & 38,09 \\
\hline \multicolumn{8}{|l|}{ Costa Rica' } \\
\hline MGS/PIB & 26,08 & 34,58 & 36,82 & 41,10 & 43,78 & 35,05 & 32,35 \\
\hline$X G S / P I B$ & 21,19 & 27,84 & 26,48 & 34,19 & 43,11 & 33,17 & 33,75 \\
\hline Comércio/PIB & 47,27 & 62,42 & 63,30 & 75,29 & 86,89 & 68,22 & 66,10 \\
\hline \multicolumn{8}{|c|}{ América Latina e Caribe } \\
\hline MGS/PIB & 11,72 & 11,73 & 15,93 & 15,12 & 19,54 & 21,26 & 23,26 \\
\hline XGS/PIB & 11,13 & 10,59 & 14,18 & 17,27 & 18,79 & 21,57 & 22,54 \\
\hline Comércio/PIB & 22,85 & 22,32 & 30,11 & 32,39 & 38,33 & 42,83 & 45,80 \\
\hline \multicolumn{8}{|l|}{ Mundo } \\
\hline MGS/PIB & - & 13,69 & 19,86 & 19,50 & 25,04 & 28,11 & 29,78 \\
\hline XGS/PIB & - & 13,65 & 18,86 & 19,34 & 25,97 & 28,92 & 30,62 \\
\hline Comércio/PIB & - & 27,34 & 38,72 & 38,84 & 41,01 & 57,03 & 60,40 \\
\hline
\end{tabular}

Fonte: WDI/World Bank.

Nota: ${ }^{1}$ Países na América Latina que são candidatos potenciais com respeito à adesão à OCDE e/ou foram formalmente convidados a se tornarem membros da organização. México, Chile e Colômbia já são membros da OCDE.

Obs.: MGS = importações de bens e serviços; XGS = exportações de bens e serviços; e MGS + XGS = comércio.

20. De acordo com Banco Mundial (2018), México e Chile (membros da OCDE), bem como o Brasil, tiveram um crescimento negativo da produtividade (PTF) no período 1995-2014. 
A tese desenvolvida por Levy (2018) é de que medidas adotadas nas últimas décadas pelos governos mexicanos foram guiadas por objetivos de estabilidade macroeconômica, adoção de um regime liberal de comércio, investimentos em capital humano, promoção de competição e expansão de programas sociais de transferência, mas não foram capazes de colocar o México em uma trajetória de crescimento sustentado com inclusão social. A razão para isso estaria associada com o fato de que o sistema tributário, bem como a previdência social e as regras trabalhistas, criam desincentivos para o setor de alta produtividade da economia e subsidiam o segmento de baixa produtividade da economia mexicana. Nesse contexto, cabe observar que as opçóes de políticas econômicas e sociais do México - o primeiro país latino-americano a aderir à OCDE, embora basicamente consistentes com as diretrizes - não geraram a transformação estrutural necessária para que o país escapasse a armadilha da renda-média.

Evidentemente, essas observaçôes não devem ser interpretadas como prova de que as políticas e diretrizes associadas com a OCDE sejam equivocadas. Afinal de contas, a trajetória da economia mexicana poderia ter sido ainda pior em um cenário caracterizado por mais intervençôes burocráticas, protecionismo, e restriçôes à competição. Os resultados para o México, porém, servem de alerta para aqueles que acreditam que a adesão à OCDE será um evento transformador para o Brasil.

\section{CONSIDERAÇÕES FINAIS}

A análise desenvolvida nas seçôes anteriores sugere que a busca da adesão à OCDE é um objetivo válido para o Brasil. É importante, no entanto, moderar as expectativas sobre a celeridade com que tal objetivo será alcançado, bem como o impacto das transformaçóes que podem advir desse processo.

Cabe também reconhecer que a eventual adesão terá implicações para a tradicional postura diplomática brasileira no âmbito das relações internacionais. Embora tais tradiçóes já estejam sendo afetadas pelas práticas da administração Bolsonaro, é provável que, como membro da OCDE, o Brasil tenha dificuldades adicionais em liderar coalizóes de países em desenvolvimento, como ocorreu no passado, por exemplo, no contexto das negociaçôes sobre liberalização multilateral do comércio de produtos agrícolas.

As relaçôes econômicas entre Brasil e China poderão também ser afetadas. Em meio à pandemia da Covid-19, enquanto as exportaçôes brasileiras para o resto do mundo (excluindo a China) diminuíram de forma significativa (uma contração de $15,2 \%$ no primeiro semestre de 2020 comparado com o primeiro semestre de 2019), as exportaçóes para a China aumentaram (em cerca de 14,6\% no mesmo período). O comércio do Brasil com a China corresponde atualmente 
a cerca de $34 \%$ das exportaçóes brasileiras e quase $80 \%$ do superavit da balança comercial brasileira (Martins, 2020). Em suma, o dinamismo do comércio exterior brasileiro está hoje mais influenciado pelo desempenho da economia chinesa do que pelas economias do G7.

A importância da relação econômica sino-brasileira se baseia em complementaridades estruturais entre as duas economias e a competitividade do setor mineral e do agronegócio brasileiro. Embora a OCDE tenha identificado a China como um dos parceiros estratégicos entre países que não são membros da organização, é improvável que o país venha a explorar a adesão à organização. $\mathrm{Na}$ realidade, um cenário mais provável é de que a OCDE virá a se caracterizar crescentemente como um "clube" de democracias baseadas em economias de mercado. Nesse contexto, ela seria uma plataforma natural para coalizóes que venham a se opor às ambiçóes geopolíticas e econômicas da China.

Tais consideraçóes não devem ser interpretadas como fatores determinantes com relação à decisão brasileira de persistir em esforços para concretizar o processo de adesão à OCDE. Ao mesmo tempo, é fundamental que tais esforços sejam combinados com um retorno o pragmatismo, que tradicionalmente caracterizou a política externa brasileira, de forma a minimizar o potencial de conflito com parceiros econômicos relevantes.

\section{REFERÊNCIAS}

BANCO MUNDIAL. Por um ajuste justo com crescimento compartilhado: uma agenda de reformas para o Brasil. Washington: Banco Mundial, 2018.

CANUTO, O.; FLEISCHHAKER, C.; SCHELLEKENS, P. The curious case of Brazil's closedness to trade. Washington, DC: The World Bank, 2015. (Policy Research Working Paper, n. 7228).

CHANDRA, V. et al. (Ed.). Innovation and growth: chasing a moving frontier. Paris: OECD; The World Bank, 2009.

COMMISSION ON GROWTH AND DEVELOPMENT. The Growth Report. Washington, D.C.: The World Bank, 2008.

COZENDEY, C. M. 2020, Brasil-OECD 2020. In: SEMINÁRIO SOBRE COMÉRCIO INTERNACIONAL DO IBRAC, 20., 2020, São Paulo. Anais... São Paulo: IBRAC, 29 out. 2020.

FRISCHTAK, C. R.; MOURÃO, J.; NORONHA, J. Reforma ou estagnaçãa: por uma nova política industrial. In: FÓRUM NACIONAL, 29., 2017, Rio de Janeiro. Anais... Rio de Janeiro: BNDES, 2017. 
GLOBAL TRADE ALERT. Collateral damage: cross-border fallout from pandemic policy overdrive. Global Trade Alert, 16 nov. 2020.

LEVY, S. Under-rewarded efforts: the elusive quest for prosperity in Mexico. Washington, D.C.: IADB, 2018.

MARTENS, K.; JACOBI, A. P. Mechanisms of OECD Governance: international incentives for national policy-making? Oxford: Oxford University Press, 2010.

MARTINS, A. Vendas para China crescem $15 \%$ e sustentam saldo comercial. Valor Econômico, 27 jul. 2020.

MELLO, F. C. The OECD enlargement in Latin America and the Brazilian candidacy. Revista Brasileira de Política Internacional, n. 63, 14 out. 2020.

OECD - ORGANISATION FOR ECONOMIC CO-OPERATION AND DEVELOPMENT. OECD 50th anniversary vision statement. Paris: OECD, 2011.

Report of the chair of the working group on the future size and membership of the organisation to council: framework for the consideration of prospective members. Paris: OECD, 2017.

PRIMO BRAGA, C. A. A nova face da globalização: implicações para o Brasil, DOM, n. 34, p. 9-15, jan./abr. 2018.

PRIMO BRAGA, C. A.; CATTANEO, O. Introduction. In: PRIMO BRAGA, C. A.; CATTANEO, O. (Ed.). The WTO and accession countries. Cheltenham, UK: Edward Elgar Publishing Limited, 2009. v. 1.

Global trade governance and development: the WTO accession conundrum In: BIRKBECK, C. D. (Ed.). Making global trade governance work for development. Cambridge: Cambridge University Press, 2011.

SANTOS, C. Brasil na OCDE: esperanças e controvérsias. Conjuntura Econômica, p. 54-63, abr. 2018.

SOLANA, J. It is time to move beyond a flawed G20. Financial Times, 8 out. 2020.

THORSTENSEN, V. et al. O Brasil a caminho da OCDE: explorando novos desafios. São Paulo: FGV/EESP, 2020.

WTO - WORLD TRADE ORGANIZATION. World Trade Statistical Review. Geneva: WTO, 2020. 